\section{Rapid inhalational induction of anaesthesia with isoflurane or halothane in humidified} oxygen

P. Vernon van Heerden FFARCSI, Mark Bukofzer MBBCh, K. Roger Edge fFasA, David F. Morrell FFASA,
This study was designed to determine the relative speeds of induction and complication rates using either halothane or isoflurane for rapid inhalational induction of anaesthesia. Forty ASA physical status I and 2, unpremedicated patients presenting for day-care dental surgery received a rapid inhalational induction (RII) with either halothane $3.5 \%$ or isoflurane $5 \%$ in humidified oxygen. The carrier gas was humidified in order to limit airway irritation caused by the pungency of the volatile agents. Isoflurane produced a faster induction than halothane $121(50)$ (SD) sec vs 176(36) sec $(P<0.01)$. Complication rates during induction (coughing, secretions, excessive movement and abandoned inductions) were similar for the two groups. The majority of patients in both the isoflurane group (17/20) and the halothane group $(14 / 20)$ found the technique of RII to be acceptable. The incidences of headache, nausea and vomiting were low and not significantly different for the two groups. Isoflurane 5\% in humidified oxygen is as acceptable for RII as halothane $3.5 \%$ and has a similar complication rate. Isoflurane may be used for RII in cases where it is deemed necessary to avoid halothane, or when a more rapid inhalational induction is required than is possible with halothane. The technique of RII with either agent in unpremedicated patients is well suited to day-care anaesthesia.

\section{Key words}

ANAESTHESIA: outpatients;

ANAESTHETICS, VOLATILE: halothane, isoflurane; ANAESTHETIC TECHNIQUES: induction.

From the Department of Anaesthesia, University of the Witwatersrand, Johannesburg Hospital, Private Bag X39, Johannesburg 2000, South Africa.

Address correspondence to: Dr. P.V. Van Heerden, Department of Intensive Care, Sir Charles Gairdner Hospital, Queen Elizabeth II Medical Centre, Verdun St., Nedlands, Western Australia 6009.

Accepted for publication 18 th November, 1991.
Cette étude a été conçue afin de déterminer les vitesses relatives d'induction et l'incidence des complications lors de l'utilisation de l'halothane ou de l'isoflurane pour l'induction rapide de l'anesthésie par inhalation. Quarante patients non prémédiqués, ASA l et 2, devant subir une chirurgie dentaire en chirurgie d'un jour, ont reçu une induction rapide par inhalation (RII) avec soit de l'halothane à 3,5\% ou de l'isoflurane à $5 \%$ administrés avec de l'oxygène humidifié. Le gaz porteur a été humidifié afin de limiter l'irritation des voies aériennes causée par l'odeur caustique des agents volatiles. L'isoflurane etait associé à une induction plus rapide que l'halothane - 121(50) (SD) sec. vs 176(36) sec. $(P<0,01)$. La fréquence des complications pendant l'induction (toux, sécrétions, mouvements excessifs et inductions abandonnées) était semblable pour les deux groupes. La majorité des patients dans le groupe isoflurane $(17 / 20)$ et dans le groupe halothane (14/20) ont trouvé la technique de RII acceptable. L'incidence de céphalées, nausées et vomissements était faible et non significativement différente dans les deux groupes. L'isoflurane à $5 \%$ administré dans de l'oxygène préhumidifié est aussi acceptable que l'halothane à 3,5\% pour RII et a une fréquence de complications semblable. L'isoflurane peut être utilisé pour RII dans les cas où il est jugé nécessaire d'éviter l'halothane, ou lorsqu'une induction par inhalation plus rapide qu'avec l'halothane est nécessaire. La technique de RII avec un agent ou l'autre chez les patients non prémédiqués s'applique bien à la chirurgie d'un jour.

Rapid inhalational induction (RII) of anaesthesia was first described using cyclopropane in $1954 .^{1}$ This technique requires the patient to take a full vital capacity breath (VCB) of a high concentration of anaesthetic agent and then hold this breath for as long as possible before unconsciousness ensues. More recently the technique has been revived for the use of the newer volatile agents halothane, isoflurane and enflurane..$^{1-7}$

The only study to compare halothane with isoflurane in equipotent concentrations for RII was performed by Loper 
et al. ${ }^{1}$ In this study, ${ }^{1}$ the patients received a heavy opioid premedication (fentanyl $5 \mu \mathrm{g} \cdot \mathrm{kg}^{-1}$ ) prior to induction, to limit the airway irritation produced by the volatile agents. The end-point of the induction sequence was lack of response to verbal command and loss of the eyelash reflex. Isoflurane produced a faster induction than halothane, with a similar complication rate. The effects on measured physiological variables such as blood pressure and heart rate were similar for the two agents. Patients found both agents to be acceptable when used for RII in the manner described by Loper et al. ${ }^{1}$

The present study was designed to determine whether humidification of the carrier gas when performing RII would also result in isoflurane being as acceptable as halothane for the technique of RII. Previously, conventional inhalational induction of anaesthesia with isoflurane has been found to be facilitated by the humidification of the carrier gas. ${ }^{8}$ Furthermore, the study was designed to evaluate more closely the technique of RII in day-care surgery. No premedication was given to the patients and the end point was the onset of surgical anaesthesia, rather than loss of the eyelash reflex as previously described. ${ }^{1}$

\section{Methods}

After obtaining institutional ethical approval and informed consent, 40 ASA physical status 1 and 2 unpremedicated patients presenting for day-care dental surgery were entered into the study. The patients received a rapid inhalational induction (RII) in a double-blind fashion (neither the anaesthetist nor the patient was aware of which agent was being administered) with either isoflurane $5 \%$ (group A) or halothane $3.5 \%$ (group B) in a $6 \mathrm{~L} \cdot \mathrm{min}^{-1}$ stream of humidified oxygen $\left(\mathrm{FIO}_{2}=1\right)$ as the carrier gas. Patients were randomly assigned to either Group A or B. The patients in the isoflurane group (Group A) also formed part of a previous publication. ${ }^{7}$

All the inductions took place on the operating table after intravenous access had been established and monitoring had been attached. Monitoring included an electrocardiogram (ECG), a pulse oximeter (Ohmeda 4700 Oxicap, BOC Health Care, USA) and continuous non-invasive blood pressure monitoring (Finapress, Ohmeda, BOC Health Care, USA). A previously calibrated (by refractometer) vaporiser, halothane or isoflurane, was adjusted by one of the authors (MB) and placed on the backbar. The backbar of the anaesthetic machine was then covered by means of a green towel. All the inductions were carried out by another of the authors $(\mathrm{PvH})$, who was unaware of which vaporiser had been attached to the backbar.

After leaving the common gas outlet of the anaesthetic machine the gas (oxygen and volatile agent) passed through a hot water bath humidifier (Bennett Cascade 1,
TABLE I Observations during the induction sequence

1 Mean arterial pressure (MAP)

- Initial and at loss of consciousness.

2 Heart rate (HR)

- Initial and at loss of consciousness.

3 Oxygen saturation $\left(\mathrm{SpO}_{2}\right)$

- Initial and lowest values.

4 Time

- From onset of vital capacity breath to loss of consciousness.

5 Complications

- Coughing $=$ single cough

- Secretions = those audible in the airway

- Laryngospasm

- Excessive movement $=$ patient needed to be restrained

Puritan Bennett Corp., USA) heated to approximately $60^{\circ}$ C. The gas was then ducted to the patient via a modified Mapleson A breathing system. The breathing system was modified by adding an additional two litre reservoir bag in series with the usual reservoir bag. This was necessary to cope with the high inspiratory flow when the patient took a VCB, as described below. The tubing of the breathing system was approximately one metre long.

Temperature and humidity tests were carried out by means of a wet and dry bulb hygrometer placed in the stream of gas. Ambient temperature in the operating room was $19^{\circ} \mathrm{C}$. Gas leaving the common gas outlet of the anaesthetic machine, before passing through the humidifier, had a temperature and relative humidity of $20^{\circ} \mathrm{C}$ and $15 \%$ respectively. The temperature of the gas at the patient end of the breathing system was approximately $27^{\circ}$ C, with a relative humidity of $98 \%$.

Baseline recordings of the variables listed in Table I were taken. The patient was then coached in the technique of taking a VCB, exhaling to residual volume and then taking a second VCB. This was done using only the facemask and angle piece with the patient breathing air. Once the patient understood the sequence, the process was repeated with humidified oxygen and volatile agent being administered during the second VCB in the above sequence. The modified Mapleson A system was primed with humidified oxygen and volatile agent by allowing the anaesthetic gas mixture to flow through the system for five minutes before the anaesthetist placed his thumb over the outlet of the system to allow both bags to fill, but not become distended. The primed system was then used to administer the desired anaesthetic mixture during the second VCB. The patient then held the breath containing the volatile agent for as long as comfortable, before resuming spontaneous respiration. Gas from the breathing system was actively scavenged via the operating room scavenging system.

During the induction sequence observations were made 
TABLE II Demographic data

\begin{tabular}{lll}
\hline & $\begin{array}{l}\text { Group A } \\
\text { isoflurane } \\
(n=20)\end{array}$ & $\begin{array}{l}\text { Group B } \\
\text { halothane } \\
(n=20)\end{array}$ \\
\hline Age yr & $26 \pm 9$ & $26 \pm 12$ \\
Sex $-\mathrm{m} / \mathrm{f}(n)$ & $12 / 8$ & $12 / 8$ \\
Weight $(\mathrm{kg})$ & $63 \pm 9$ & $64 \pm 12$ \\
ASA I $(n)$ & 20 & 18 \\
$\quad$ Il $(n)$ & 0 & 2 \\
Smokers $(n)$ & 7 & 7 \\
\hline
\end{tabular}

by one of the authors (MB) who also noted any complications (Table I). Once the patient had resumed spontaneous respiration following the induction sequence he was asked, every five seconds, to open his eyes and when he no longer responded to these commands his pupils were examined continuously to determine when they became central in position. The induction sequence was deemed to be complete when all three of the following criteria were met - no response to verbal command, regular (automatic) respiration, and centrally placed pupils. The stop-watch timing the induction sequence was stopped as soon as the pupils became central in position. The duration of the induction sequence was from the onset of the VCB containing the volatile agent until surgical anaesthesia was achieved. The second set of physiological variables (mean arterial pressure, heart rate and arterial oxygen saturation) were measured at the end-point of the induction sequence ("at loss of consciousness"-Table I). The exhaled volatile agent concentration was not measured as the rate of rise of volatile agent concentration in exhaled gases has been well documented during RII. ${ }^{3}$ If any of the defined complications occurred, the induction was deemed to be "complicated."

Following the RII, succinylcholine $1 \mathrm{mg} \cdot \mathrm{kg}^{-1}$ was administered to facilitate tracheal intubation. Anaesthesia was then maintained in all patients with halothane, $2 \%$ inspired, and nitrous oxide in oxygen.

All the patients were visited approximately two hours after surgery by one of the authors who was unaware of which agent the patient had received. Patients were asked (i) to recall their last conscious memory in the induction sequence, (ii) if they would choose the same technique for a subsequent anaesthetic, and (iii) if they had experienced any headache, nausea or vomiting. The authors made no attempt to assess the speed and quality of the recovery phase.

Results were analysed by means of paired and unpaired $t$ tests, analysis of variance (ANOVA), chi squared (with Yates' correction) and Fischer's exact tests as appropriate. Data are expressed as mean values $\pm \mathrm{SD}$. A $P$ value of $<0.05$ was deemed to be significant.
TABLE III Results

\begin{tabular}{lccl}
\hline & $\begin{array}{l}\text { Group A } \\
\text { isoflurane } \\
(n=20)\end{array}$ & $\begin{array}{l}\text { Group B } \\
\text { halothane } \\
(n=20)\end{array}$ & P value \\
\hline Time to LOC (sec) & $121 \pm 50$ & $176 \pm 36$ & $<0.01$ \\
Breaths to LOC ( $n)$ & $18 \pm 12$ & $30 \pm 12$ & $<0.01$ \\
Complicated inductions & & & \\
(n) & 9 & 9 & NS \\
Coughing & 3 & 5 & NS \\
Secretions & 1 & 0 & NS \\
Excessive movement & 6 & 5 & NS \\
Abandoned & 2 & 3 & NS \\
Mean arterial pressure & & & \\
Pre-induction (mmHg) & $94 \pm 12$ & $88 \pm 13$ & NS \\
At LOC (mmHg) & $89 \pm 14$ & $87 \pm 13$ & NS \\
Heart rate & & & \\
Pre-induction (bpm) & $76 \pm 19$ & $75 \pm 13$ & NS \\
At LOC (bpm) & $83 \pm 18$ & $80 \pm 11$ & NS \\
\hline
\end{tabular}

LOC $=$ loss of consciousness.

\section{Results}

The two groups were similar with regard to age, weight, ASA physical status, sex ratios and numbers of smokers $(P>0.05)$ (Table II). Isoflurane (Group A) produced a faster RII than halothane (Group B) $(P<0.01$ - Table III). The mean induction times were $121 \pm 50 \mathrm{sec}$ for Group A and $176 \pm 36 \mathrm{sec}$ for Group B. The number of breaths to loss of consciousness was less in the isoflurane group, $18 \pm 12$, compared with $30 \pm 12$ in the halothane group $(P<0.01-$ Table III).

There were nine complicated inductions in each group, although only two of the 20 inductions in Group $A$ and three of the 20 inductions in Group B had to be abandoned due to their severity (Table III). Inductions were abandoned due to uncontrolled coughing (two in Group A and one in Group B) or excessive movement (two in Group B). In those inductions abandoned the two in Group A were smokers and one of the three in Group B was a smoker.

There were no episodes of laryngospasm or desaturation $\left(\mathrm{SpO}_{2}<90 \%\right)$ in either group. The groups were similar in their incidence of coughing and excessive movement. Mean arterial pressures (MAP) pre-induction and at loss of consciousness were similar between and within groups. There was no difference between patients' heart rates (HR) pre-induction and at loss of consciousness within each group or between groups (Table III).

The postoperative interview yielded similar results for the two groups (Table IV). Seventeen of the 20 patients in Group A said that they would choose the same technique for a subsequent anaesthetic, compared with 14 of 20 in 
TABLE IV Postoperative interview

\begin{tabular}{llll}
\hline & $\begin{array}{l}\text { Group A } \\
\text { isoflurane } \\
(n=20)\end{array}$ & $\begin{array}{l}\text { Group B } \\
\text { halothane } \\
(n=20)\end{array}$ & Pvalue \\
\hline Amnesia after first VCB ( $n)$ & 16 & 15 & NS \\
Would repeat experience $(n)$ & 17 & 14 & NS \\
Headache $(n)$ & 1 & 3 & NS \\
Nausea and vomiting $(n)$ & 0 & 1 & NS \\
\hline
\end{tabular}

$\mathrm{VCB}=$ vital capacity breath.

Group B. Sixteen of 20 in Group A and 15 of 20 in Group $B$ had no recall for events after the VCB containing the volatile agent. The incidence of headache, nausea and vomiting in the two groups is shown in Table IV. The interview included those patients in whom the RII had to be abandoned and their replies contribute to the results (Table IV).

\section{Discussion}

Rapid inhalational induction (RII) has a number of indications. These include the induction of anaesthesia in patients for day-care surgery in whom a rapid recovery, free of the hangover effect of intravenous agents, is required in patients with a needle phobia and in older children, who are able to understand and comply with the technique of RII. Halothane remains the agent of choice for inhalational induction, but its use in North America and Europe is declining due to the possibility of halothane hepatitis. ${ }^{10}$ In these countries, isoflurane is becoming the volatile agent of choice.

However, there are problems related to the use of isoflurane for inhalational induction, due to the pungent odour and airway complications (coughing, secretions, laryngospasm and subsequent hypoxaemia) associated with this agent. ${ }^{9}$ One method of decreasing the incidence of these complications has been to administer isoflurane by RII. ${ }^{5}$ When isoflurane is used for RII the patients are either well premedicated ${ }^{l}$ or the inspired concentration is limited by the inclusion of nitrous oxide in the carrier gas. ${ }^{5}$ Humidification of the carrier gases during inhalational induction with isoflurane has also been shown to decrease the complications associated with this agent. ${ }^{8}$

The results above show that isoflurane is as acceptable as halothane in terms of complication rate and patient acceptability. Isoflurane also produces a faster RII than halothane, as may be predicted from its lower blood/gas solubility coefficient. The relatively high complication rate seen in both groups is a reflection of the narrow definition given to these complications, rather than the unacceptability of the technique. Even in those inductions which were abandoned, they were abandoned before the onset of severe haemodynamic disturbances or hypoxaemia: cardiovascular stability (HR and MAP) is a feature of this technique (Table III).

The wide variation of induction times may be improved by better patient selection. Perhaps the variation would have been smaller if anxious patients and smokers had been excluded.

Onset of sugical anaesthesia (loss of consciousness, regular respiration and central pupils) was chosen as the end-point of our induction sequence. Although this is a relatively "soft" end-point, it is clinically useful because it is the stage at which body surface surgical procedures, such as are performed during day-care anaesthesia, may commence. This is also the stage at which a relaxant may be given to facilitate tracheal intubation. The induction times are therefore relevant to day-care anaesthesia, rather than setting only an experimental end-point, such as loss of response to verbal commands or loss of the eyelash reflex, as in previous studies of RII. ${ }^{1-6}$

The induction times obtained in this study are due solely to the effect of the relevant volatile agent. No premedication was included in the protocol. This, together with the different end-points, makes comparisons of the induction times obtained in this study with the results of previous studies $^{1,3-6}$ difficult. The only other study to compare isoflurane with halothane for RII ${ }^{\mathrm{l}}$ also found that isoflurane produced a faster RII. The incidence of complications. and the acceptability of the technique in this previous study ${ }^{1}$ would have been influenced by the premedication administered to patients.

It should be noted that this study was carried out at moderate altitude; the barometric pressure in Johannesburg is approximately $620 \mathrm{mmHg}$. The induction times obtained may be longer than would be obtained at sea level due to the relatively lower partial pressures of the volatile agents in the gas delivered to the patient. The water vapour in the humidified carrier gas may also decrease the partial pressure of the volatile agent. These factors bear further investigation.

The authors conclude that isoflurane $5 \%$ in humidified oxygen is an acceptable choice for RII and has a complication rate similar to halothane $3.5 \%$. Isoflurane may be used for RII in cases where it is deemed necessary to avoid halothane. This technique may be valuable for day-care anaesthesia, especially if used in co-operative, nonanxious patients.

We believe that the simple technique of humidifying the carrier gas is responsible for making isoflurane as acceptable as halothane for RII. This makes the use of heavy premedication $^{1}$ or lower inspired concentrations ${ }^{5}$ unnecessary when using isoflurane for RII. The low blood:gas 
solubility coefficient of isoflurane may then be exploited to produce a truly rapid inhalational induction.

\section{Acknowledgements}

We wish to thank Professor J. Lownie, Dr. C. Nicolopoulos and the staff at the Dental Hospital of the University of the Witwatersrand, Johannesburg for all their cooperation and assistance with this study. We also thank Abbott Laboratories SA (Pty) Ltd for financial assistance.

\section{References}

1 Loper K, Reitan J, Bennett H, Benthyusen J, Snook L. Comparison of halothane and isoflurane for rapid anesthetic induction. Anesth Analg 1987; 66: 766-8.

2 Drummond GB. Rapid inhalational induction of anaesthesia. Br J Anaesth 1988; 61: 373-5.

3 Ruffle JM, Snider MT, Rosenberger JL, Latta WB. Rapid induction of halothane anaesthesia in man. Br J Anaesth 1985 ; 57: 607-11.

4 Wilton NCT, Thomas VL. Single breath induction of anaesthesia, using a vital capacity breath of halothane, $\mathrm{ni}$ trous oxide and oxygen. Anaesthesia 1986; 41: 472-6.

5 Lamberty $J M$, Wilson $I H$. Single breath induction of anaesthesia with isoflurane. $\mathrm{Br} J$ Anaesth 1987; 59: 1214-8.

6 Rowbottom SJ, Yukioka H, Fujimori M. Comparison of conventional and rapid inhalational induction of anaesthesia with enflurane. Anaesthesia 1990; 45: 43-5.

7 van Heerden PV, Morrell DF, Becker $P$. Rapid inhalational induction with isoflurane in humidified carrier gas. Br J Anaesth 1991; 67: 470-2.

8 van Heerden PV, Wilson IH, Marshall FPF, Cormack JR. Effect of humidification on inhalational induction with isoflurane. Br J Anaesth 1990; 64: 235-7.

9 Phillips AJ, Brimacombe JR, Simpson DL. Anaesthetic induction with isoflurane or halothane. Anaesthesia 1988; 43: 927-9.

10 Editorial. Halothane associated liver damage. Lancet 1986; i: 1251-2. 